\title{
Introduction: Health Equity Does Not Equal Health Equality
}

Janice M. Phillips and Margaret P. Moss

\section{CHAPTER OBJECTIVES}

- Define health equity and its importance in shaping the health and well-being of populations

- Elucidate the connection among health equity, health disparities, and the social and structural determinants of health

• Highlight implications for nursing in achieving health equity

\section{KEY CONCEPTS}

Health equity

Health inequities

Social determinants of health
Structural determinants of health

Social justice

\section{Introduction}

The goal of achieving health equity has received considerable attention within the past decade and will remain a major concern nationally and internationally well into the 21st century. Although there are several definitions of health equity, for the purposes of this book, we use the definition of health equity as defined by the Robert Wood Johnson Foundation (RWJF). The RWJF defines health equity as follows:

Health equity means that everyone has a fair and just opportunity to be as healthy as possible. This requires removing obstacles to health such as poverty, discrimination, and their consequences, including powerlessness and lack of access to good jobs with fair pay, quality education and housing, safe environments, and health care. (2017, para. 1)

Noted scholar and health equity professor Paula Braveman (2014) called for greater clarity regarding definitions of health disparities and health equity and underscored that explicit definitions call for the integration of an ethical and a human rights perspective.

To advance the work in this area, Healthy People 2020 defines health disparities as:

a particular type of health difference that is closely linked with social, economic, and/ or environmental disadvantage. Health disparities adversely affect groups of people who have systematically experienced greater obstacles to health based on their racial or ethnic group; religion; socioeconomic status; gender; age; mental health; cognitive, sensory, or 
physical disability; sexual orientation or gender identity; geographic location; or other characteristics historically linked to discrimination or exclusion. (Office of Disease Prevention and Health Promotion [ODPHP], n.d.-b, para. 6)

Explicit definitions of health equity and health disparities are critical to helping ensure that resources are properly allocated to populations in need, particularly economically disadvantaged populations (Braveman, 2014). However, throughout this text, contributors will use the accepted or emerging definitions relevant to their work. Importantly, the terms "health equity" and "health disparities" are interwoven in that any progress toward achieving health equity will be measured by our progress in reducing and ultimately eliminating health disparities. In contrast, the term "health inequality," as defined by UK researcher Margaret Whitehead, refers to health differences that are unavoidable, unjust, and unnecessary (Whitehead, 1991). Social justice principles are the underpinnings for achieving health equity and eliminating inequities that result in poor health outcomes. One cannot achieve health equity until disparities are eliminated, health inequities are successfully addressed, and social justice principles are integrated paving the way for individuals, communities, and populations to experience their fullest health potential.

Equally relevant to achieving health equity are the social determinants of health. There is a growing consensus that addressing the social determinants of health, factors outside of clinical determinants of health, is critical to achieving health equity especially for our most vulnerable populations. The World Health Organization (WHO) provides one of the most frequently cited definitions on the social determinants of health.

The social determinants of health are the conditions in which people are born, grow, live, work and age. These circumstances are shaped by the distribution of money, power and resources at global, national and local levels. The social determinants of health are mostly responsible for health inequities - the unfair and avoidable differences in health status seen within and between countries. (2012, para. 1)

There is ample evidence that shows that health is defined as being more than traditional clinical care, which is believed to account for approximately $20 \%$ of health outcomes, with the remaining $80 \%$ of health outcomes are attributed to the social, behavioral, and economic factors (University of Wisconsin Population Health Institute, 2019).

Thus initiatives devoted to achieving health equity must include a focus on addressing the social determinants of health, personal, social, structural, economic, and environmental factors that influence health status and health outcomes (ODPHP, n.d.-a). To that end, we also offer a chapter on the less studied structural determinants of health and a model for thinking about how it fits with social determinants of health and health outcomes. These concepts reflect the nursing metaparadigm: person, health, nurse, and environment; as well as the holistic perspective of the person. Collectively, health equity, health disparities, health inequities, and the social determinants of health work together.

The urgency to achieve health equity underscores the need for nurses at all levels and practice settings to develop the necessary acumen, knowledge, expertise, and partnerships that will enable them to be full participants in achieving the highest level of health for all populations. In fact, it is imperative that nurses become active advocates in all arenas surrounding healthcare. 
Given that nursing represents the largest sector of the health professions with more than 3.5 million RNs in the United States (American Association of Colleges of Nursing, 2019), nurses are well positioned to play a leadership role in this endeavor and are invited to do so. In the United States, where nursing continues to evolve as one of the most respected, well-recognized, and trusted professions, nurses have increased opportunities to extend their influence in helping all populations experience optimal health, thus moving us toward achieving health equity for the nation. Numerous nurse leaders are calling for more nursing engagement in this arena and have identified a number of implications for nursing practice, education, research, and policy advocacy (Lathrop, 2013; National League for Nursing [NLN], 2019; Persaud, 2018; Schroeder, Kohl Malone, McCabe, \& Lipman, 2018; Williams, Phillips, \& Koyama, 2018).

\section{- Discussion Questions}

- Does your employing institution, professional organization, or local or state government have a health equity strategic plan? If so, how might you utilize your expertise and influence in helping to achieve the health equity goals outlined in the health equity plan and related initiatives?

- How might you infuse the concepts "health equity," "health inequity," and the "social determinants of health" into clinical practice and nursing research?

- What steps might you as a nurse take to help achieve health equity?

- Resources

American Association of Colleges of Nursing. (2006). The essentials of doctoral education for advanced nursing practice. Retrieved from https://www.aacnnursing.org/ Portals/42/Publications/DNPEssentials.pdf

Braveman, P., Arkin, E., Orleans, T., Proctor, D., \& Plough, A. (2017). What is health equity? And what difference does a definition make? Princeton, NJ: Robert Wood Johnson Foundation.

Haddad, L. M., \& Toney-Butler, T. (2019). Nursing shortage. In StatPearls. Treasure Island, FL: StatPearls Publishing. Retrieved from https://www.ncbi.nlm.nih.gov/ books/NBK493175

- References

American Association of Colleges of Nursing. (2019). Nursing fact sheet. Retrieved from https://www.aacnnursing.org/News-Information/Fact-Sheets/Nursing-Fact-Sheet

Braveman, P. (2014). What are health disparities and health equity? We need to be clear. Public Health Reports, 129(Suppl. 2), 5-8.

Lathrop, B. (2013). Nursing leadership in addressing social determinants of health. Policy, Politics and Nursing Practice, 14(1), 41-47. doi:10.1177/1527154413489887

National League for Nursing. (2019). A vision for integration of the social determinants of health into nursing education curricula. Retrieved from http://www.nln.org/ docs/default-source/default-document-library/social-determinants-of-health. pdf?sfvrsn=2 


\section{Part I. Policy Issues and Implications for Nursing}

Office of Disease Prevention and Health Promotion. (n.d.-a). Healthy People 2020: Social determinants of health. Retrieved from https://www.healthypeople.gov/2020/topicsobjectives/topic/social-determinants-of-health

Office of Disease Prevention and Health Promotion. (n.d.-b). Healthy People 2020: Social disparities. Retrieved from https://www.healthypeople.gov/2020/about/foundation -health-measures/Disparities

Persaud, S. (2018). Addressing the social determinants of health through advocacy. Nursing Administration Quarterly, 42(2), 123-128. doi:10.1097/naq.0000000000000277

Robert Wood Johnson Foundation. (2017). What is health equity? Retrieved from https:// www.rwjf.org/en/library/research/2017/05/what-is-health-equity-.html

Schroeder, K., Kohl Malone, S., McCabe, E., \& Lipman, T. (2018). Addressing the social determinants of health: A call to action for school nurses. The Journal of School Nursing, 34(3), 182-191. doi:10.1177/1059840517750733

University of Wisconsin Population Health Institute. (2019). 2019 County Health Rankings Key Findings Report. Retrieved from https://www.countyhealthrankings.org/ reports/2019-county-health-rankings-key-findings-report

Whitehead, M. (1991). The concepts and principles of equity and health. Health Promotion International, 6(3), 217-228. doi:10.1093/heapro/6.3.217

Williams, S., Phillips, J., \& Koyama, K. (2018). Nurse advocacy: Adopting a health in all policies approach. The Online Journal of Issues in Nursing, 23(3), Manuscript 1. Retrieved from http://ojin.nursingworld.org/MainMenuCategories/ANAMarketplace/ANAPeriodicals/OJIN/TableofContents/Vol-23-2018/No3-Sept-2018/Policy -Advocacy.html

World Health Organization. (n.d.). Social determinants of health. Retrieved from https:// www.who.int/social_determinants/sdh_definition/en 